\title{
Acesso e acolhimento em unidades de saúde na visão dos usuários
}

\author{
Access and quality care in health care centers from the users' point of view
}

Acceso y acogida en unidades de salud bajo el punto de vista de los usuarios

\section{Maria Alice Dias da Silva Lima ${ }^{1}$, Donatela Dourado Ramos ${ }^{2}$, Raquel Borba Rosa ${ }^{3}$, Taís Maria Nauderer ${ }^{4}$, Roberta Davis ${ }^{5}$}

\section{RESUMO}

Objetivo: Caracterizar, a partir da opinião dos usuários, o acesso ao atendimento e a prestação do serviço oferecido, quanto à forma como são acolhidos em unidades de saúde de Porto Alegre. Métodos: Entrevistas semi-estruturadas com usuários em duas unidades de saúde, realizadas entre outubro e dezembro de 2002 e de julho a novembro de 2003. Os dados foram submetidos à análise de conteúdo temático. Resultados: Foram identificados fatores ligados ao acesso funcional, tais como a espera prolongada, a necessidade de chegar muito cedo para garantir o atendimento. $\mathrm{O}$ acesso geográfico foi considerado adequado pelos usuários. Quanto ao acolhimento, desempenho profissional, durante o atendimento, e o vínculo estabelecido entre o usuário e o serviço de saúde, foram os principais fatores valorizados pelos usuários. Conclusão: $\mathrm{O}$ acolhimento relaciona-se com o vínculo entre o usuário e o serviço de saúde, com a resolutividade do atendimento e com a adequação do serviço às necessidades dos clientes.

Descritores: Acesso aos serviços de saúde; Qualidade da assistência à saúde, acesso e avaliação; Satisfação do paciente

\begin{abstract}
Objective: To describe the user's opinion regarding access and quality care in health centers in Porto Alegre, Brazil. Methods: Data were collect through semi-structured interviews among users of two health care centers from October to December, 2002 and from July to November, 2003. Data were examined with content analysis. Results: Users reported they were subjected to long waiting periods; they had to arrive very early to be seen. The geographic access was considered appropriate. Users appreciated professional courtesy and quality care, and the bond established between them and the health's care service. Conclusion: Quality care was connected to the bond established between the user and the health care centers, which addressed appropriately the needs of the clients.

Keywords: Health service access; Quality of care, Health care quality, access, and evaluation; Patient satisfaction
\end{abstract}

\section{RESUMEN}

Objetivo: Caracterizar, a partir de la opinión de los usuarios, el acceso a la atención y prestación del servicio ofrecido, en cuanto a la forma cómo son acogidos en unidades de salud de Porto Alegre. Métodos: Se llevaron a cabo entrevistas semi-estructuradas con usuarios en dos unidades de salud, entre octubre y diciembre del 2002 y de julio a noviembre del 2003. Los datos fueron sometidos a análisis de contenido temático. Resultados: Fueron identificados factores ligados al acceso funcional tales como la espera prolongada, la necesidad de llegar muy temprano para garantizar la atención. El acceso geográfico fue considerado adecuado por los usuarios. En cuanto a la acogida, el desempeño profesional, durante la atención, y el vínculo establecido entre el usuario y el servicio de salud fueron los principales factores valorizados por los usuarios. Conclusión: La acogida se relaciona con el vínculo entre el usuario y el servicio de salud, con la capacidad de resolución de la atención y con la adecuación del servicio a las necesidades de los clientes.

Descritores: Accesibilidad a los servicios de salud; Calidad de la asistencia a la salud, acceso y evaluación; Satisfacción del paciente

\footnotetext{
${ }^{1}$ Doutora em Enfermagem, Professora Associada, Escola de Enfermagem, Universidade Federal do Rio Grande do Sul - UFRGS - Porto Alegre (RS), Brasil.

${ }^{2}$ Mestre em Enfermagem pela Universidade Federal do Rio Grande do Sul. Enfermeira da Secretaria Municipal de Saúde de Porto Alegre. Porto Alegre (RS), Brasil.

${ }^{3}$ Pós-Graduanda em Enfermagem da Universidade Federal do Rio Grande do Sul-UFRGS - Porto Alegre (RS), Brasil.

${ }^{4}$ Pós-Graduanda em Enfermagem da Universidade Federal do Rio Grande do Sul-UFRGS - Porto Alegre (RS), Brasil.

${ }^{5}$ Enfermeira do Setor de Emergência do Hospital Nossa Senhora da Conceição de Porto Alegre (RS), Brasil.
} 


\section{INTRODUÇÃO}

Acesso e acolhimento são elementos essenciais do atendimento, para que se possa intervir positivamente no estado de saúde do indivíduo e da coletividade ${ }^{(1)}$. A avaliação pelos usuários, permitindo ouvir sua opinião sobre os serviços prestados em função de suas necessidades e expectativas, é uma das atividades que podem assegurar a qualidade dos serviços de saúde ${ }^{(2)}$. Assim, é fundamental conhecer como os usuários avaliam o atendimento, para repensar as práticas profissionais e intervir sobre a forma de organização dos serviços, visando ao seu aperfeiçoamento.

Obter acesso aos serviços é uma primeira etapa a ser vencida pelo usuário quando parte em busca da satisfação de uma necessidade de saúde. $\mathrm{O}$ acolhimento surge a partir das relações que se estabelecem entre usuário e profissionais no atendimento e está ligado à utilização dos recursos disponíveis para a solução dos problemas dos usuários ${ }^{(3)}$. O acolhimento evidencia as dinâmicas e os critérios de acessibilidade a que os usuários estão submetidos e pode constituir diretriz para o estabelecimento de um processo de trabalho centrado no interesse do usuário, tornando-se, assim, tecnologia para a reorganização dos serviços, com vistas à garantia de acesso universal, resolutividade e humanização do atendimento ${ }^{(4)}$.

Considerando que acesso e acolhimento podem favorecer a reorganização dos serviços de saúde e a qualificação da assistência prestada, o objetivo deste estudo foi caracterizar, a partir da opinião de usuários, como se conforma o acesso ao atendimento e como vem sendo prestada a assistência que lhes é oferecida, quanto à forma como são acolhidos, em unidades de saúde de Porto Alegre.

\section{MÉTODOS}

A coleta de dados foi realizada em duas unidades de uma gerência distrital do município de Porto Alegre/RS, identificadas como unidade A (no período de outubro a dezembro de 2002) e unidade B (de julho a novembro de 2003). A área de abrangência dessa gerência atende a uma população com condições socioeconômicas precárias. Para seleção dos locais de estudo, levou-se em consideração o interesse dos trabalhadores das Unidades de Saúde em conhecer a opinião de seus usuários acerca da assistência prestada, identificado através de contato entre as coordenações de unidades básicas e os pesquisadores.

A coleta de dados foi feita por meio de entrevista semi-estruturada, seguindo um roteiro utilizado em estudo prévio ${ }^{(5)}$. As entrevistas foram realizadas nestas unidades de saúde, logo após o término do atendimento.
Foram entrevistados 16 usuários, na Unidade A, e 17 na Unidade B. Para delimitar a suficiência dos dados foi utilizado o critério de saturação( ${ }^{(6)}$.

O estudo foi aprovado pelo Comitê de Ética em Pesquisa da UFRGS e pelo Comitê de Ética em Pesquisa da SMS de Porto Alegre. O consentimento dos informantes foi obtido mediante folha explicativa, garantindo-se o anonimato e assegurando-se a liberdade de desistir do estudo a qualquer momento.

Para tratamento do material, utilizou-se a técnica de análise de conteúdo temático ${ }^{(7)}$. Constituiu-se de três etapas: pré-análise (sistematização das idéias iniciais, recorrendo-se à leitura repetida e exaustiva, a fim de obter maior aproximação do material); exploração do material (codificação do material, por regras previamente definidas) e interpretação dos dados.

Os usuários foram identificados por códigos: USU A, para a unidade A, e USU B para a unidade B, seguidos do número correspondente à ordem das entrevistas.

\section{RESULTADOS}

Para apresentação dos resultados, foram estabelecidas as categorias acesso e acolhimento. Problemas relacionados ao acesso foram referidos pelos usuários como os principais fatores dificultadores da assistência, sendo os relativos ao acesso funcional os mais citados. Entre as dificuldades de acesso funcional, o tempo de espera prolongado pelo atendimento foi bastante referido pelos usuários.

Entretanto, alguns usuários consideraram que tudo é válido para receber assistência, de forma que a espera pelo atendimento se torna um fator pouco relevante. $\mathrm{O}$ fato de ter que chegar à unidade ainda de madrugada, muito antes do horário de abertura do serviço para garantir consulta, foi referido por quase todos os usuários. Alguns se mostraram descontentes frente a essa questão, sugerindo alternativas para modificá-la.

A maioria dos usuários, porém, considerou que comparecer de madrugada ao serviço de saúde é um dever de quem quer receber a assistência. Além disso, referiram que essa situação acontece em todas as unidades de saúde e a consideraram como uma característica do sistema público de saúde. A grande demanda reprimida e o fato de ter de chegar muito cedo foram relacionados pelos usuários à escassa oferta de consultas médicas e, principalmente, odontológicas, conforme evidenciado a seguir:

Deveria ter mais ficha, ao invés de ter um ginecologista de tarde, ter dois. Ai tu vê, são vinte fichas, dez agendadas e dez a gente tem que vir de manhã. Se tivesse um doutor a mais, a gente não precisava ter que vir pra cá às 4 da manhã. E dentista, se tu quiser pra adulto, a gente tem que vir $3 \mathrm{~h}$ da tarde num dia pra no outro dia 
tu conseguir a ficha. E às vezes não consegue (...) (USU A - 14)

Alguns usuários negaram a dificuldade de conseguir consultas, atribuindo à impaciência a causa de muitos não receberem o atendimento:

É o seguinte: tem pessoas que não têm paciência. Tem que ter paciência, saber esperar, saber que é assim mesmo.(USU A-2)

Além dos aspectos relacionados ao agendamento, os usuários, ao serem questionados sobre o atendimento, destacaram o ato de examinar, que foi citado como uma demonstração de bom desempenho profissional e de responsabilização de quem presta a assistência:

Pra mim foi muito maravilhoso. Me examinou, assim, em tudo, conversou comigo, me disse que se eu não me sentir bem em uma, não precisa duas semanas, épra mim voltar aqui de novo. E ela quer me ver bem alegre, bem contente. (USU A -1)

A responsabilização do profissional para com o estado de saúde do usuário se constitui em um dos elementos essenciais de um efetivo acolhimento. Além disso, desperta no usuário um sentimento de confiança em relação ao profissional que presta a assistência.

Apesar das evidências positivas em relação ao atendimento, os resultados também apontaram para uma avaliação negativa por parte dos usuários:

Eu achei que o atendimento foi rápido, assim, pra marcar foi rápido! Eu acho que só faltava mesmo era examinar! (USU B16).

No comeco eu achei legal. Bom o atendimento. Mas depois ele (médico) nem olhou, só fez assim e já me deu direto o remédio (USU $B-10)$.

Os usuários consideraram que as consultas devem ultrapassar a resolução do problema apresentado no momento, como fica evidente no seguinte depoimento:

Ele (filho) tá com três meses né, ai eu perguntei pra ela (pediatra) se ele já pode começar com suco, porque se eu não perguntasse pra ela, ela não ia me dizer... Eu perguntei, entendeu? Se não fosse eu perguntar, ia ficar por isso mesmo, entendeu? Então, são coisas assim que faz falta deles perguntarem pra gente, sabe. A falta de informação é muita. (USU B - 3).

Os grupos organizados nas unidades assumem um importante papel, uma vez que têm por objetivo esclarecer dúvidas, dar orientações, prevenir complicações para a saúde do indivíduo e sua família, promovendo maior qualidade de vida.

Olha, eu acho muito bom, gosto muito desses grupos, tanto o dos hipertensos quanto o dos diabéticos, porque eu participo dos dois, né. E sempre tem alguma coisa pra aprender. (USU A -16).

As falas, a seguir, exemplificam uma forma de organização dos serviços estudados, que levam em conta as necessidades dos usuários:

(...) Eu cheguei aqui com problema de pressão e eu trabalho e elas (membros da equipe de enfermagem) sabem. Elas me passaram direto pra médica. E dai ela me deu essa carteirinha pra quando eu tiver ruim vim marcar. Porque eu não tinha essa carteirinha. Agora, eu chego a qualquer hora, tá aqui a carteirinha. (USU B -9).

Não vim de manhã, porque ela (filba) ficou ontem no Hospital Santo Antônio até a meia-noite. E como eu gosto de sempre passar pela (usuária cita o nome de uma pediatra), que eu sei que conhece ela, hoje en vim aqui, expliquei para as enfermeiras e elas conseguiram uma ficha pra mim botar a nenê. (USU A - 4).

Os usuários mostraram-se satisfeitos com a marcação de exames e com o sistema de referência e contra-referência, que inclui o encaminhamento a especialidades médicas e à realização de cirurgias.

Eu sempre consultei, sempre fiz os exames que me marcaram e os remédios, sempre ganhei os remédios, o doutor me atende muito bem e eu até fui operada, encaminhada por aqui, tudo encaminhado pela assistência social. (USU A - 2).

(...) Eu fiz o meu Pré-Natal com a doutora (usuária cita o nome de uma ginecologista obstetra). Inclusive eu ganhei muito bem men filho através dela, com um papelzinho daqui que ela me deu, fui encaminhada pro Hospital Fêmina e ganhei super bem através dela o men guri de dez anos. (USU A - 4).

Com relação à estrutura física, as sugestões para melhoria diferiram entre as unidades A e B. Na unidade A, a maior reivindicação foi pela construção de uma cobertura na parte externa do posto, que sirva de proteção para os usuários aguardarem pelo atendimento em dias frios e chuvosos, antes do horário de abertura (7 horas). Já na unidade B, o descontentamento de alguns usuários é pelo espaço físico interno do local, considerado pequeno para a demanda, tornando incômoda e desconfortável a espera pelo atendimento.

O acesso geográfico foi avaliado a partir de tempo e forma de deslocamento e a distância entre a residência do usuário e o serviço de saúde. Ficou evidenciado que os usuários caminham por 15 minutos, em média, para deslocamento às unidades. Apenas três usuários da unidade $B$ informaram morar longe do serviço de saúde e, portanto, necessitam utilizar transporte coletivo. Uma usuária, que não reside mais na área de abrangência do serviço, relatou utilizar dois coletivos para chegar à unidade, levando cerca de 30 minutos no percurso. 
Manifestou, porém, que prefere deslocar-se para uma unidade mais distante de sua residência, por gostar do atendimento.

Com relação ao acesso econômico destaca-se a facilidade ou dificuldade na obtenção de medicamentos mediante apresentação de prescrição médica. $\mathrm{Na}$ unidade A, os usuários foram unânimes referindo facilidade no recebimento do medicamento prescrito. Já na unidade $\mathrm{B}$, mais da metade dos usuários referiu que, atualmente, faltam medicamentos com freqüência, situação considerada incomum pelos usuários, caracterizando um período pelo qual toda a rede básica de saúde de Porto Alegre passava, no final do ano de 2003.

A falta de critérios na distribuição de medicamentos e preservativos foi uma crítica feita à unidade A por um de seus usuários. Isso dificulta que o cliente se organize dentro de sua renda mensal e compreenda quando algum medicamento ou preservativo lhe for negado.

$O$ fato de ter que utilizar transporte coletivo para chegar às unidades poderia ser considerado uma dificuldade financeira, porém apenas três usuários referiram esta necessidade, dizendo que se dirigiam à unidade $\mathrm{B}$, não por ser a mais próxima das suas residências, mas porque se sentiam bem atendidos e por já possuírem vínculo com o serviço. Por esses motivos, os usuários encontraram alternativas econômicas para se deslocarem até o posto.

\section{DISCUSSÃO}

$\mathrm{O}$ acesso funcional envolve o acesso propriamente dito aos serviços de que o usuário necessita, incluindose os tipos de serviços oferecidos, os horários previstos e a qualidade do atendimento. Os depoimentos colhidos neste estudo coincidem com resultados já descritos ${ }^{(1)}$ sobre dificuldades de acesso funcional, que predominaram em relação a outras dificuldades, especialmente quanto à obtenção de consulta odontológica e médica.

Ficou demonstrado, corroborando estudo anterior ${ }^{(1)}$, que os usuários se submetem às dificuldades na obtenção de acesso ao atendimento, muitas vezes pelo fato de que o serviço procurado representa a alternativa mais viável, especialmente sob o aspecto econômico ${ }^{(8)}$, para buscar a resolução de suas necessidades de saúde.

Entretanto, o atendimento prestado parece não estar satisfazendo todas as necessidades do usuário, que quer receber informação e orientação que o profissional de saúde, por meio do conhecimento adquirido, pode prestar para a manutenção do seu bem-estar. Tais orientações lhe permitiriam maior autonomia em relação à própria saúde.

Em pesquisa ${ }^{(9)}$ realizada em um ambulatório de pediatria do SUS, a demora para receber atendimento foi o principal problema apontado pelos usuários. A espera prolongada foi também identificada ${ }^{(10)}$ como o motivo número um de insatisfação da clientela, além da reclamação de haver insuficiência quanto à possibilidade de agendamento de novas consultas.

A necessidade de chegar muito cedo pela manhã também foi um problema identificado em outro estudo $^{(9)}$. Uma das possíveis soluções seria a abolição do sistema de distribuição de fichas no início da manhã, caso essa atividade pudesse ser diluída ao longo do dia. Há, porém, experiências em várias unidades de saúde, inclusive numa das estudadas, em que havia disponibilidade de consultas médicas às 13 horas para 0 turno da tarde, mas os usuários chegavam às 10 ou 11 horas para iniciar a espera, o que parece demonstrar uma cultura instituída da fila, difícil de romper.

Analisando as regiões onde se encontram os serviços de saúde, verifica-se que as duas unidades estão bem localizadas, pois foram construídas em pontos estratégicos, por onde circulam transportes coletivos de diferentes bairros, facilitando o deslocamento dos usuários. Porém, nem sempre o aspecto geográfico determina a escolha do cliente em utilizar um serviço, pois esse fator se torna, muitas vezes, pouco relevante, quando comparado à qualidade da assistência ${ }^{(5)}$.

Acesso geográfico e acolhimento estão relacionados, coincidindo com achados descritos ${ }^{(1-5)}$ que identificaram: apesar de existirem serviços de saúde próximos da casa do usuário, sua escolha é influenciada pela forma como ele é recebido na unidade, pela confiança na experiência dos trabalhadores, o tipo de atendimento ofertado, a capacidade e a competência dos membros da equipe e a resolutividade desses serviços.

Para análise do acesso econômico, foram considerados os custos ou os benefícios que os usuários têm com relação à obtenção de medicamentos e de preservativos, ao acesso a procedimentos próximos a sua residência e à forma de deslocamento. Devido ao fato de as unidades em estudo atenderem a uma população com condições socioeconômicas precárias, torna-se clara a importância dada pelo usuário à satisfação de suas necessidades, principalmente quanto à obtenção de medicamentos para tratamentos de problemas crônicos. Estudo anterior ${ }^{(11)}$ identificou a migração que os usuários fazem na cidade, entre diferentes unidades de saúde, em busca de medicamentos não disponíveis no local onde se deu o atendimento.

Apesar de acesso e acolhimento serem elementos de assistência inter-dependentes, se faz importante estabelecer as suas diferenças para melhor analisar como vêm sendo acolhidos os usuários nos serviços investigados. O acolhimento não se limita apenas a uma recepção cordial, mas extrapola esse conceito, incluindo a escuta ativa do usuário ${ }^{(11)}$. Aspectos como vínculo, 
resolutividade e desempenho profissional estão relacionados com o acolhimento.

Ficou claro que o desempenho profissional é avaliado pelo usuário, através do interesse demonstrado no exame físico, nas perguntas feitas e orientações dadas, bem como na resolutividade das condutas, confirmando resultados já descritos ${ }^{(1)}$.

O bom atendimento, baseado na escuta do usuário, e o bom desempenho profissional propiciam o vínculo do binômio usuário-serviço de saúde. Esse vínculo otimiza o processo da assistência, proporcionando aos profissionais conhecerem os seus clientes e as prioridades de cada um, facilitando-lhes o acesso. Ficou evidenciado, nos serviços estudados, uma preocupação com a humanização do atendimento, bem como com uma forma de organização que leve em conta as necessidades do usuário.

Além disso, vincular-se à unidade de saúde gera satisfação e segurança ao usuário, pois ele se percebe aceito e próximo dos cuidadores. O vínculo implica estabelecer relações tão próximas e tão claras que todo o sofrimento alheio causa sensibilização. É a responsabilização do profissional da saúde junto ao usuário pelo seu bem-estar. Contudo, isso não deve ser encarado como uma relação de dependência, pois o objetivo é educar e estimular o paciente para o autocuidado, conferindo autonomia ao usuário $^{(12)}$

Em relação ao acolhimento, o processo de trabalho e a competência profissional das equipes estudadas, promovendo resolutividade, foram elementos geradores de satisfação dos usuários, apesar de algumas dificuldades pontuais referidas, do mesmo modo que apontado em pesquisa anterior ${ }^{(1)}$. Por conseqüência, fez-se necessário repensar o processo de trabalho na equipe de saúde, em especial na equipe de enfermagem, reformulando, implementando ou criando tecnologias que possam favorecer mudanças na lógica do atendimento, de modo a torná-lo mais centrado no sujeito e na equipe ${ }^{(4-5)}$.

\section{CONSIDERAÇÕES FINAIS}

A escuta da opinião de quem recebe a assistência é um elemento importante na avaliação dos serviços de saúde, bem como da forma que o sistema de saúde se organiza para viabilizar o atendimento. Foram identificados vários fatores ligados ao acesso funcional, que dificultam o acesso propriamente dito ao serviço de saúde, tais como a espera prolongada pelo atendimento e a inadequada área física do serviço. Quanto ao acolhimento, o vínculo do usuário com o serviço de saúde e o desempenho profissional de quem presta o atendimento foram os principais fatores valorizados pelos usuários. Esses elementos são imprescindíveis quando se fala em atenção à saúde, pois encaminham para a resolutividade e a satisfação das necessidades da clientela. O vínculo confere segurança aos usuários, permitindo que os trabalhadores do serviço os conheçam, para melhor estabelecer as prioridades na atenção à sua saúde.

A caracterização dos elementos 'acesso e acolhimento' proposta nesta pesquisa contribui, ainda que parcialmente, para a avaliação dos serviços, em busca de melhorias. Entretanto, para que estudos como este possam trazer efetivas contribuições ao atendimento em saúde, faz-se necessário que os profissionais de saúde repensem suas práticas, buscando atuar em consonância com os princípios e diretrizes do SUS, libertando-se do modelo de queixa-conduta, tão arraigado nas unidades de saúde. Especialmente o enfermeiro, como membro da equipe de saúde e coordenador da assistência de enfermagem, necessita avaliar sua participação no processo de trabalho, em unidades de saúde, no sentido de contribuir com medidas que mais favoreçam o acesso e o acolhimento aos usuários.

Conclui-se que ainda há muito a ser trabalhado em termos de acesso e acolhimento nas unidades de saúde, com vistas a efetivamente qualificar o atendimento e alcançar a integralidade e a resolutividade da assistência, contribuindo para a concretização de um modelo humanizado, centrado nas necessidades do usuário.

\section{REFERÊNCIAS}

1. Ramos DD, Lima MADS. Acesso e acolhimento aos usuários em uma unidade de saúde de Porto Alegre, Rio Grande do Sul, Brasil. Cad Saúde Pública $=$ Rep Public Health. 2003; 19(1): 27-34.

2. Adami NP. A melhoria da qualidade nos serviços de enfermagem. Acta Paul Enfermagem. 2000; 13(N Esp Pt 1):190-6.

3. Matumoto S. O acolhimento: um estudo sobre seus componentes e sua produção em uma unidade da rede básica de serviços de saúde. [Tese]. Ribeirão Preto: Escola de Enfermagem de Ribeirão Preto da Universidade de São Paulo; 1998.

4. Franco TB, Bueno WS, Merhy EE. O acolhimento e os processos de trabalho em saúde: o caso de Betim, Minas Gerais, Brasil. Cad Saúde Pública = Rep Public Health. 1999; 15(2): 345-53.

5. Ramos DD. Acesso e acolhimento aos usuários em uma unidade de saúde de Porto Alegre/RS no contexto da municipalização da saúde [Tese]. Porto Alegre: Escola de Enfermagem da Universidade Federal do Rio Grande do Sul; 2001.

6. Polit DF, Hungler BP. Nursing research: principles and methods. 6th ed. Philadelphia: Lippincott; c1999.

7. Bardin L. Análise de conteúdo. 3 a ed. Lisboa: Edições 70; 2004.

8. Santos MP. Avaliação da qualidade dos serviços públicos de atenção à saúde da criança sob a ótica do usuário. Rev Bras Enfermagem. 1995; 48(2):109-19.

9. Franco SC, Campos GWS. Avaliação da qualidade de atendimento ambulatorial em pediatria em um hospital universitário. Cad Saúde Pública = Rep Public Health. 1998; 
14(1):61-70.

10. Kloetzel K, Bertoni AM, Irazoqui MC, Campos VPG, Santos RN. Controle de qualidade em atenção primária à saúde. I - A satisfação do usuário. Cad Saúde Pública Rep Public Health. 1998; 14(3): 623-8.
11. Lopes MJM, Silva JLA. Estratégias metodológicas de educação e assistência na atenção básica de saúde. Rev Latinoam Enfermagem. 2004; 12 (4):683-8.

12. Rizzotto MLF. As políticas de saúde e a humanização da assistência. Rev Bras Enfermagem. 2002; 55(2): 196-9. 